\title{
LAVAGEM DE DINHEIRO E SUAS GERAÇÕES
}

\section{MONEY LAUNDERING AND GENERATIONS}

\author{
Sérgio Fernando Moro ${ }^{1}$ \\ Irene Portella ${ }^{2}$
}

Flávia Jeane Ferrari ${ }^{3}$

\section{RESUMO}

O presente artigo tem por finalidade estudar os aspectos da lavagem de dinheiro e suas gerações. Nos últimos anos o crime de lavagem de dinheiro tomou uma certa popularidade nos meios de comunicações, tornando-se um tema de grande repercussão no cenário econômico e penal brasileiro. Este tipo de crime não é apenas um problema nacional, mas ocorre no mundo todo. O combate à lavagem de dinheiro é a repressão mais intensa que o Estado pode fazer face às organizações criminosas. O crime de lavagem de dinheiro evoluiu com a tecnologia, porém a polícia e a justiça seguem em passos lentos, por este motivo houve a necessidade de atualizar o direito brasileiro através de novas legislações e utilizando a tecnologia ao seu favor. O objetivo deste artigo é a lavagem de dinheiro e suas gerações, gerações estas que

\footnotetext{
${ }^{1}$ Ministro da Justiça e da Segurança Pública do Brasil desde 01/2019. Foi Juiz Federal da 13. ${ }^{\text {a }}$ Vara Criminal Federal de Curitiba/PR, especializada em crimes financeiros, de lavagem de dinheiro e praticados por grupos criminosos organizados. Trabalhou como Juiz instrutor no Supremo Tribunal Federal durante o ano de 2012. O autor cursou o Program of Instruction for Lawyers na Harvard Law School em julho de 1998 e possui título de mestre e doutor em Direito do Estado pela Universidade Federal do Paraná - UFPR. Escreveu livros e artigos especializados na área jurídica. Participou do International Visitors Program organizado em 2007 pelo Departamento de Estado norte-americano com visitas a agências e instituições dos EUA encarregadas da prevenção e do combate à lavagem de dinheiro. Lecionou entre 2007 a 2016 como Professor Adjunto de Direito Processual Penal da Universidade Federal do Paraná - UFPR. É Professor contratado da graduação e pós-graduação do Unicuritiba - Centro Universitário Curitiba. Recebeu o título de Doctor of Laws, honoris causa, pela University of Notre Dame du Lac, South Bend, Indiana, em 2018.

${ }^{2}$ Doutora em Direito Constitucional pelo departamento de Direito Público e Teoria do Estado, pela Universidade de Santiago de Compostela.

${ }^{3}$ Mestranda em Direito Empresarial e Cidadania pelo Unicuritiba (2019). Especializações nas áreas de Ministério Público \& Estado Democrático de Direito (2019); Direito Militar (2018); Processo Civil (2017); Direito Ambiental (2017); Direito do Trabalho (2013) e Bel. Direito pela Facear (2012). Integrante do Programa Institucional de Iniciação Científica - PCI junto ao Centro Universitário Curitiba - Unicuritiba, Linha de Pesquisa: Compliance (2019). Atualmente sou Adjunta da Seção de Sindicância, Processos Administrativos e IPM, da Assessoria de Apoio para Assuntos Jurídicos da $5^{\text {a }}$ Região Militar - $5^{\text {a }}$ Divisão de Exército - $1^{\circ}$ Tenente - Oficial Técnico Temp do Exército Brasileiro. Email: flaviajeane.ferrari@hotmail.com
} 
consideramos no presente artigo como evoluções do crime e a busca do Estado para uma punição mais justa. $\mathrm{O}$ artigo utiliza a metodologia bibliográfica de forma a explanar de modo conceituado, apresentando as hipóteses e modalidades enquadradas na legislação pátria e internacional, com explicações doutrinárias elucidativas, as quais provocam polêmicas no meio jurídico e social brasileiro.

Palavras chaves: Direito Penal Moderno; Organizações Criminosas; Lavagem de Dinheiro e Gerações. 


\begin{abstract}
The purpose of this article is to study the aspects of money laundering and its generations. In recent years the crime of money laundering has gained a certain popularity in the media, becoming a subject of great repercussion in the Brazilian economic and criminal scene. This type of crime is not only a national problem, but occurs worldwide. The fight against money laundering is the most intense repression that the state can face against criminal organizations. Money laundering crime has evolved with technology, but police and justice are moving slowly, so there was a need to update Brazilian law through new legislation and using technology to their advantage. The purpose of this article is money laundering and its generations, which we consider in this article as evolutions of crime and the pursuit of the state for a fairer punishment. The article uses the bibliographic methodology in order to explain in a conceptual way, presenting the hypotheses and modalities framed in the national and international legislation, with elucidative doctrinal explanations, which provoke controversies in the Brazilian legal and social environment.
\end{abstract}

Keywords: Modern Criminal Law; Criminal organizations; Money Laundering and Generations. 


\section{INTRODUÇÃO}

Atualmente passamos pelo processo de globalização mundial, o que nos traz uma nova realidade, através de um estreitamento das relações transnacionais, o recebimento rápido de informações, pessoas ou coisas, tanto para o bem como para o mal.

Com o mundo criminal não seria diferente. Com a globalização, surgiram novos crimes e outros evoluíram para se adaptarem a nova realidade e tecnologias.

Por este motivo, o presente artigo tratará de um desses crimes, o qual passou por várias modificações e está mais presente do que nunca em nossa vida, o crime de lavagem de dinheiro.

O crime de lavagem de dinheiro está previsto no artigo $1^{\circ}$ da Lei $n^{\circ} 9.613$, de 1998: “Ocultar ou dissimular a natureza, origem, localização, disposição, movimentação ou propriedade de bens, direitos ou valores provenientes, direta ou indiretamente, de infração penal", impondo a esta prática pena de reclusão de três meses a dez anos, e multa.

O referido crime é um dos mais antigos relacionados ao sistema financeiro de um País, porém nos últimos anos ele é noticiado quase que cotidianamente nas grandes mídias, por um motivo muito simples, o crime de lavagem de dinheiro evoluiu com a tecnologia, ganhando grandes proporções, entretanto a sua visibilidade também.

Para isso, o combate ao crime de lavagem de dinheiro é a repressão mais dura que o Estado pode fazer contra às organizações criminosas. Uma vez que, sem dinheiro, as organizações criminosas não conseguem se manter e mormente as atividades ilícitas que necessitam dessa prática para comprar, vender e aplicar seus lucros.

Inclusive, considera-se a lavagem de dinheiro um problema internacional, ocorrendo em todos os países e atinge todos nós. O referido crime recebe denominação análoga em outros países, sendo que todos significam a ideia de limpeza do dinheiro, cito: "reciclaggio del denaro" na Itália, "branqueamento de capitais" em Portugal, "money laudering" nos Estados Unidos e "blanqueo de capitales" na Espanha.

Como citado acima, a tecnologia fez com que as barreiras mundiais fossem rompidas através da globalização, o que ocasionou na facilitação econômica entre os países, entre outros aspectos. Porém, com os criminosos não foi diferente, o que aumentou a propagação dos crimes ainda mais. Hoje em dia em vez não há mais a figura 
do criminoso carregando o dinheiro consigo, a organização criminosa deposita em contas, seja no Brasil ou no exterior, distorcendo assim de uma maneira mais rápida e fácil a sua origem.

Com este novo cenário nos crimes financeiros, surgiu uma preocupação mundial em reprimir tal prática, e no Brasil não foi diferente. Por este motivo o legislador aprovou a lei $\mathrm{n}^{\circ}$ 9.613, de 03 de março de 1998. Posteriormente, com a intenção de aprimorá-la e para torná-la mais eficiente foi aprovada a lei $n^{\circ} 12.683$ de 9 de julho de 2012.

Através dessas grandes alterações, há a necessidade de demostrar as gerações do crime de lavagem de dinheiro e a transição que o Brasil sofreu perante as novas legislações para se readequar a nova realidade, ante as principais polêmicas em torno do tema, haja vista a dificuldade em detectar essas atividades ilícitas e principalmente de punir quem dela participa. 


\title{
2. O CRIME DE LAVAGEM DE DINHEIRO
}

Os indícios do surgimento do crime de lavagem de dinheiro, é da década de 20, na Itália, quando criminosos da máfia italiana teriam comprado uma rede de lavanderias, para usá-la como fachada, com a finalidade de facilitar a circulação do capital advindo de atividades ilícitas.

Nesse contexto, esse tipo de comércio disfarçado possibilitava movimentar o dinheiro ilícito sob a alegação de que se tratava do lucro advindo da atividade das lavanderias.

Ainda, em relação a origem, o autor Conserino (2011, p. 02) salienta:

\begin{abstract}
Já no século, $X X$, a origem da expressão lavagem de dinheiro ou money laundering, conforme consta, é proveniente do lendário Al Capone, que com o dinheiro auferido com o contrabando de bebidas e cigarros, adquiriu no final da década de 1920, na cidade americana de Chicago, uma rede de lavanderias para lhe permitir a realização de depósitos bancários de pequenos valores monetários compatíveis com a venda nas lavanderias, no entanto, tais depósitos resultavam de suas atividades ilícitas do comércio de bebidas, exploração do jogo e prostituição.
\end{abstract}

Como o crime de lavagem de dinheiro crescia pelo mundo, nas mais diversas atividades, a preocupação dos países em criar mecanismos para conter sua prática, surgindo dessa maneira políticas de combate ao referido crime.

Durante a Convenção de Viena, no ano de 1988, esse tema ganhou grande dimensão, uma vez que já tinha a noção de que a criminalidade estava organizada de forma globalizada, para isso medidas precisavam ser tomadas para tentar combater o narcotráfico e seus ganhos, e para acabar com a prática, deveriam punir os lucros adquiridos com ela, o que tornaria o combate mais eficiente (MENDRONI, 2006).

No mesmo ano, foi realizada a Declaração de Basiléia, proposta ao setor financeiro internacional, que trazia regras com a finalidade de prevenir o processo de lavagem de dinheiro associado ao uso de transações bancárias (MENDRONI, 2006).

Nesse diapasão, a Organização dos Estados das Américas designou a Comissão Interamericana para Controle do Uso de Drogas, para que, através dela, fosse efetuada a prática de programas apropriados para combater as práticas das organizações criminosas ligadas ao tráfico, entre as quais a lavagem de dinheiro, tomando, medidas que visavam harmonizar as legislações e consequentemente torná-las mais efetivas. 
Concomitantemente foi criado o Grupo de Egmont, em Bruxelas, que criava a cooperação entre os países para descobrir a rota percorrida pelo narcotráfico, bem como de outros crimes, além disso, a união dos países que podiam agir de forma mais articulada para combater as transferências financeiras feitas pelas organizações criminosas (MENDRONI, 2006).

Destaca-se ainda a Convenção de Palermo, que ditou regras de combate do crime organizado, sendo incorporada pelo Brasil em 15 de março de 2004, pelo Decreto $n^{\circ}$ 5.015. O Brasil aderiu à Convenção de Mérida, criada pela ONU, com o objetivo de combater a corrupção, em 31 de janeiro de 2006 (BADARÓ; BOTTINI, 2012).

O crime de lavagem de dinheiro é antigo, porém sem mantém cada dia mais atual, o que pode ser conceituado como sendo a prática de transformar o dinheiro ilícito em aparentemente lícito.

Trata-se do encadeamento de atos que visam incutir o capital na sociedade, para que este se misture ao dinheiro que circula de forma lícita, ao ponto de que não seja mais possível sua distinção, ou que chegue ao conhecimento das autoridades sua origem e seu destino.

Para o autor Lopes (2009, p. 520) "Simplificadamente, lavagem de dinheiro refere-se ao ato de "limpar o dinheiro sujo", tornando lícitos (legais) recursos provenientes de alguma atividade ilícita desenvolvida por indivíduos ou organizações criminosas".

Neste sentido, o Conselho de Controle de Atividades Financeiras (COAF), (BRASIL, 2012), conceitua o crime de lavagem de dinheiro:

\section{[...] um conjunto de operações comerciais ou financeiras que buscam a incorporação na economia de cada país, de modo transitório ou permanente, de recursos, bens e valores de origem ilícita e que se desenvolvem por meio de um processo dinâmico que envolve, teoricamente, três fases independentes que, com frequência, ocorrem simultaneamente.}

Segundo Mendroni (2006, p. 31), a definição de que o crime de lavagem de dinheiro sob a ótica que ao mesmo tempo em que ofende a administração da justiça agride a ordem socioeconômica.

$\mathrm{O}$ crime de lavagem de dinheiro tem como competência para seu julgamento a Justiça Federal; trata-se de um crime de dano, pois necessita para sua consumação a ocorrência de lesão superveniente ao bem jurídico protegido; é um crime autônomo, 
independe de processo e julgamento de crime antecedente; é possível a forma tentada; é plurissubsistente, integrando atos, conteúdos e métodos variados; e é considerado um crime permanente.

O sujeito ativo pode ser qualquer pessoa que realize a conduta prevista na legislação pertinente. O sujeito passivo é a sociedade que é prejudicada pela prática, que ocasiona problemas econômicos, e consequentemente, prejudica a segurança e soberania do Estado.

O processo de lavagem de dinheiro, é necessário a prática de uma infração penal, ocasião que se recebe o capital ilícito, iniciando, a fase de ocultação dos valores que de forma ilícita foram adquiridos. Em seguida, são realizadas diversas operações para que se disfarce a origem dos bens, completando o ciclo com a reinserção do dinheiro na economia formal sob a aparência de lícito.

A primeira etapa do processo de lavagem de dinheiro se dá com a fase de colação, também conhecida como placement, conversão ou introdução, haja vista a necessidade de deslocar o dinheiro do local de sua obtenção, colocando-o na economia, a fim de que as autoridades não detectem de onde o mesmo surgiu (CONSERINO, 2011). Além disso, é comum nesta fase que o dinheiro sucedido de atividade ilícita seja transferido para outro local.

Para o autor Mendroni (2006, p. 58) articula que:

Nesta etapa, utilizam-se as atividades comerciais e as instituições financeiras, tanto bancárias, como não bancárias, para introduzir montantes em espécie, geralmente divididos em pequenas somas, no circuito financeiro legal. Na maioria das vezes, o agente criminoso movimenta o dinheiro em países com regras mais permissivas e naqueles que possuem um sistema financeiro liberal [...].

A organização criminosa tem como objetivo nesta fase, fazer que o dinheiro seja transformado em outra forma de valor, utilizando muitas vezes, da ajuda e conivência de funcionários de bancos ou a compra de bens materiais.

A segunda fase é conhecida por layering, ou seja, ocultação, camuflagem. Iniciando o mascaramento, a difusão da fonte da qual o dinheiro se originou.

Por fim, a terceira fase é conhecida como reinversão, integration ou integração, ocorre quando a organização criminosa consegue de forma decisiva introduzir o dinheiro na economia e começa a gozar de seus benefícios, sendo o dinheiro obtido de 
forma ilícita e já conta com o aspecto de legalidade, desde então pretendido (CONSERINO, 2011). 


\section{AS GERAÇÕES DA LEGISLAÇÃO DE LAVAGEM DE DINHEIRO}

Ao realizar uma análise do assunto no direito comparado, verifica-se a existência de três gerações de legislações de combatem à lavagem de dinheiro, cuja análise é imprescindível, para que se possa compreender a modificação que a lei $n^{\circ} 12.683 / 2012$, trouxe ao Brasil.

A primeira geração é composta pelos países que preveniam o crime antecedente da lavagem de dinheiro apenas com o tráfico de drogas, justamente porque foram as primeiras leis a incriminarem a referida conduta.

Após a Convenção de Viena, os países signatários tipificaram a lavagem ou ocultação de bens originários apenas conexos ao crime de tráfico de drogas e afins.

A segunda geração versa sobre as leis que tiveram seu surgimento posteriormente, e que além do tráfico de drogas, possuem de um rol taxativo de crimes antecedentes, ampliando a repressão ao crime de lavagem de dinheiro.

Por fim, a terceira geração é combinada por leis que não possuem um rol taxativo, e que, de uma maneira mais clara, constituem que qualquer ilícito penal pode ser antecedente à lavagem de dinheiro (CAVALCANTE, 2012). Cito países como a Argentina, Bélgica, Estados Unidos, França, Itália, México, Suíça, que são modelos de países que dispõe desse tipo de legislação e atualmente acrescenta-se o Brasil com as alterações trazidas pela nova legislação. 


\section{O BRASIL E O CRIME DE LAVAGEM DE DINHEIRO}

O Brasil passa a contar com uma legislação de terceira geração, com o advento da Lei ${ }^{\circ} 12.683 / 2012$, tendo como uma das principais características a não necessidade de um crime antecedente para que se configure o delito de lavagem de dinheiro.

Nota-se que antes da alteração da Lei $\mathrm{n}^{\circ}$ 9.613/1998, apenas haveria a configuração do delito de lavagem de dinheiro se anteriormente fosse verificado um dos crimes elencados pelos incisos, esta situação colocava o Brasil na segunda geração, porque, tinha-se que levar em consideração os crimes anteriores previstos.

Após o advento da Lei $\mathrm{n}^{\circ} 12.683 / 2012$, o termo crime foi substituído por infração penal, infração esta que compreende um crime antecedente ou uma contravenção penal, motivo que justifica a revogação do rol de crimes e coloca o Brasil na terceira geração.

Outra alteração consubstancial trazida pela referida lei, foi o afastamento automático do servidor público de suas funções pelo seu indiciamento pelo crime de lavagem de dinheiro, neste sentido o legislador foi rigoroso, uma vez que, o fato de alguém estar sendo indiciado, não quer dizer que foi o autor do fato.

Além disso, o princípio da presunção de inocência trazido pela nossa Constituição ficaria diretamente afetado. Cito que seria como estar conferindo uma pena ao servidor sem ao menos estar condenado com trânsito e julgado pela prática de uma suposta lavagem de dinheiro.

Outra medida, mais acautelatória que o legislador poderia indicar que o servidor que teria o contato direto com o dinheiro, não deve ser afastado, e sim remanejado para a outra atividade de forma preventiva, com isso, num primeiro momento, não traz um rótulo de culpado ao servidor, e nem prejuízos à administração pública.

Versando sobre contravenções penais, cito como exemplos, o jogo do bicho, bingo e máquinas de caça-níqueis, que a partir de agora terão penas mais rígidas e serão punidas com mais rigor, tornando crime de lavagem de dinheiro à ocultação ou dissimulação do dinheiro advindo de tais práticas.

Para Badaró e Bottini (2012, p. 82), a renúncia do legislador face ao rol taxativo é coerente, no que tange à proteção do bem jurídico tutelado, todavia, considera que o legislador foi além do admissível, ao criar um arcabouço normativo pesado demais para 
os fins que se propõe. Destacando-se que "a partir da vigência da lei, todo o processo penal que tiver por objeto crimes com produtos patrimoniais atrairá a discussão sobre o destino dos bens e a possível lavagem de dinheiro".

Apesar disso, com a nova redação dada pela lei $n^{\circ} 12.683 / 2012$ e o aumento do rol dos crimes antecedentes, surgiu uma dificuldade para enquadrar o caso concreto à legislação.

Saliento que esse tipo de situação pode ser verificado no julgamento da ação penal 470, conhecida como Mensalão, ocasião em que os ministros tiveram um debate com diferentes teses ao imputar o delito aos réus. Confirmando assim, a polêmica em torno do assunto, em relação se o legislador agiu de forma certeira ao acabar com o rol taxativo, que posteriormente deverão ser aclaradas pela doutrina ou pela jurisprudência.

Segundo o Ministro Marco Aurélio (JUSBRASIL, 2012) afirmou:

\begin{abstract}
Preocupa-me sobremaneira o diapasão que se está dando ao tipo lavagem de dinheiro. Creio que uma posição rigorosa, e diria mesmo extensiva, presente a disciplina legal, repercutirá nacionalmente, considerada a atuação dos diversos órgãos investidos do ofício judicante. Como sempre digo: um suspiro no âmbito do Supremo repercute em termos de se assentar enfoques e jurisprudência. A meu ver, os fatos, tais como expostos por relator e revisor, não são típicos, sob o ângulo da lavagem do dinheiro. $O$ direito penal não admite sobreposições.
\end{abstract}

De acordo com o Ministro Lewandowski, se manifestou nos seguintes termos: "É preciso provar o dolo específico. O réu sabia, ou deveria saber que esse dinheiro era proveniente de crime contra a administração pública e contra o sistema financeiro [...]".

Ainda, elucida a Ministra Rosa Weber que: "O dolo, a consciência e a vontade tem que abranger o delito de lavagem, a necessidade de transformar o sujo em limpo".

Outra alteração importante ocasionada pela referida lei, é o acesso a dados cadastrais dos investigados pelo Ministério Público e pela Autoridade Policial, garantindo a esfera da intimidade. A lei foi clara nesse aspecto e permitiu apenas, e exclusivamente algumas informações, pois trata-se de dados públicos, que as autoridades terão acesso direto, dados esses que podem ser encontrados em qualquer outro lugar, cartório, internet, etc, sendo dados públicos que não invadem a intimidade.

O legislador preocupou-se inclusive com o dever do advogado, que deve comunicar as atividades de lavagem de dinheiro que chegar ao seu conhecimento, devendo comunicar o COAF a situação. Porém não foi visto com bons olhos pelos 
profissionais da área, uma vez que há uma certa quebra na confiabilidade entre cliente e advogado. Outra discussão também é que, algumas vezes, o advogado não sabe que seu cliente está lavando dinheiro, não podendo o profissional ser penalizado por algo que não era de seu conhecimento.

Saliento ainda, que estas alterações aceleram o andamento do judiciário e dos processos como um todo, uma vez que essas autoridades terão acessos mais rápido a tais informações, trazendo assim mais efetividade a investigação, pois sabemos que as organizações criminosas não possuem burocracia.

Por fim, nota-se que as alterações acarreadas pela lei $\mathrm{n}^{\circ} 12.683 / 2012$, traz muitas discussões sobre o mesmo assunto. Acrescenta-se a isto o fato das mudanças muitas vezes confrontarem alguns princípios constitucionais, o que vem despertando o interesse e incorporando os argumentos dos profissionais do meio jurídico. 


\section{CONCLUSÃO}

O presente artigo buscou trazer uma visão geral sobre o crime de lavagem de dinheiro, e em seguida debateu algumas alterações que foram trazidos pela lei $\mathrm{n}^{\circ}$ $12.683 / 2012$.

Nota-se que podemos chegar a algumas conclusões, sendo inicialmente que a legislação consubstanciada na lei n ${ }^{\circ} 9.613 / 1998$, trazia um rol de crimes antecedentes, poderia punir por lavagem de dinheiro apenas as transações advindas daqueles delitos.

Com a criação da lei $\mathrm{n}^{\circ} 12.683 / 2012$, revogou-se o rol restrito dos crimes, advertiu penalizar as pessoas que praticam contravenções penais, mas, que a partir delas, praticam a lavagem de dinheiro, como é o caso de jogos de azar, entre outros.

Nesse ponto a lei evoluiu, porque agora o perpetrando pode ser punido pelos crimes que praticou. Porém, ressalta-se no que tange a pena mínima, pois sendo o delito anterior mais grave - crime ou um menos grave - contravenção, ambos terão a mesma pena mínima, precisa verificar se não haverá uma desproporção, pois em alguns casos a pena pelo crime de lavagem de dinheiro, sendo mínima de três anos, poderá ser superior ao do crime principal.

Apesar disso, é nítida a evolução do país nesse aspecto, pois extinguindo o rol de crimes antecedentes, o Brasil passou a compor a lista dos países com as legislações mais modernas, ou seja, a terceira geração, no combate ao crime de lavagem de dinheiro.

Partindo para os pontos polêmicos da referida lei, é a alteração consubstancial trazida pela referida lei, foi o afastamento automático do servidor público de suas funções pelo seu indiciamento pelo crime de lavagem de dinheiro, neste sentido o legislador foi rigoroso, uma vez que, o fato de alguém estar sendo indiciado, não quer dizer que foi o autor do fato.

Outra alteração importante ocasionada pela referida lei, é o acesso a dados cadastrais dos investigados pelo Ministério Público e pela Autoridade Policial, garantindo o direito a intimidade. Uma vez que trata-se de dados públicos, que as autoridades terão acesso direto, esses dados podem ser encontrados em qualquer lugar, cartório, internet, etc, pois são dados públicos e que não invadem a intimidade da pessoa, neste sentido, a lei foi clara nesse aspecto e permitiu somente, e exclusivamente algumas informações. 
Destaca-se, que isso irá acelerar o andamento dos processos como um todo, uma vez que as autoridades terão o acesso mais rápido a tais informações, trazendo assim mais efetividade, pois as organizações criminosas não possuem a burocracia administrativa, o que torna as ações criminosas mais rápidas.

Por fim, em relação ao dever do advogado de comunicar as atividades de lavagem de dinheiro que chegar ao seu conhecimento ao COAF, há as discussões se fere o princípio do sigilo profissional entre advogado e cliente.

Enfim, o crime de lavagem de dinheiro não é recente, porém merece um estudo aprofundado por todos os profissionais do direito, pois as organizações criminosas acompanham a rapidez da tecnologia. Com o advento da lei $n^{\circ} 12.683 / 2012$, que colocou o Brasil na terceira geração, os debates ainda são incertos e surgem muitas dúvidas em relação a sua eficácia diante do desenvolvimento da sociedade. 


\section{REFERÊNCIAS}

ARAS, Vladimir. Requisição dos dados cadastrais: 0 segredo do polichinelo. Disponível em <https://vladimiraras.blog/2012/07/26/requisicao-de-dadoscadastrais-o-segredo-de-polichinelo/>.

BADARÓ, Gustavo Henrique; BOTTINI, Pierpaolo Cruz. Lavagem de Dinheiro: Aspectos penais e processuais penais. Comentários à Lei 9.613/1998, com as alterações da Lei 12.683/2012. São Paulo: Revista dos Tribunais, 2012.

BRASIL. Constituição da República Federativa do Brasil de 1988: promulgada em 05 de outubro de 1988 . Disponível em <http://www.planalto.gov.br/ccivil_03/constituicao/constituicao.htm>.

BRASIL. Lei 9.613/1998. Lei de lavagem de dinheiro: promulgada em 03 de março de $1998 . \quad$ Disponível em <http://www.planalto.gov.br/ccivil_03/Leis/L9613compilado.htm>.

BRASIL. Lei 12.683 (2012). Altera a lei 9.613/1998; referente à lavagem de dinheiro: promulgada em 09 de julho de 2012. Disponível em <http://www.planalto.gov.br/ccivil_03/_Ato2011-2014/2012/Lei/L12683.htm>.

BRAGA, Romulo Rhemo Palitot. DEODATO, Felie Augusto Forte de Negreiros. Análise do delito lavagem de dinheiro desde uma abordagem sobre o sujeito ativo da infração penal prévia como autor, coautor ou partícipe. Disponível em <file:///C:/Users/user/Downloads/110-362-1-PB.pdf>.

CAVALCANTE, Márcio André Lopes. Comentários à Lei n.12.683/2012, que alterou a Lei de Lavagem de Dinheiro. Dizer o Direito. Disponível em: < http://www.dizerodireito.com.br/2012/07/comentarios-lein126832012-quealterou.html.>. 
CHEMIN, Rodrigo. MÃOS LIMPAS E LAVA JATO: A CORRUPÇÃO SE OLHA

NO ESPELHO. Ed. Citadel. Porto Alegre, 2018.

COAF. Disponível em: 〈http://www.fazenda.gov.br/orgaos/coaf>.

COELHO, Márcio. Debate sobre lavagem esquenta sessão do STF. Disponível em: $<$ http://congressoemfoco.uol.com.br/noticias/debate-sobre-lavagem-esquenta-sessaodo-stf/>.

CONSERINO, Cassio Roberto; (Coord.) VASCONCELOS, Clever Rodolfo Carvalho; MAGNO, Levy Emanuel. Lavagem de Dinheiro. São Paulo: Atlas, 2011.

COSTA, Daniela Carvalho Almeida da. SODRÉ, Edyleno Italo Santos. Reflexão acerca de da administrativização do direito penal brasileiro (com a Lei $\left.n^{\circ} 12.683 / 2012\right)$. Revista Jurídica do Unicuritiba, vol. 02, n . 43, Curitiba, 2016. pp 50-71. Disponível em < http://revista.unicuritiba.edu.br/index.php/RevJur/article/view/1815/1192>.

EDITORIAL, Nova lei de lavagem de dinheiro: $\mathbf{O}$ excesso e a banalização. Boletim do Instituto Brasileiro de Ciências Criminais (IBCCRIM), Ano 20, nº 237, 2012.

GALLERANI, Vanessa Almeida. Lavagem de dinheiro e seus aspetos polêmicos. Disponível em <https://jus.com.br/artigos/29742/lavagem-de-dinheiro-e-seus-aspectospolemicos>.

GRANDIS, Rodrigo de. Considerações obre o dever do advogado de comunicar atividade suspeita de "Lavagem" de dinheiro. Boletim do Instituto Brasileiro de Ciências Criminais (IBCCRIM), Ano 20, nº 237, 2012.

JUSBRASIL. Ministro Marco Aurélio vota pela absolvição dos seis réus acusados de lavagem de dinheiro. Disponível em: < https://stf.jusbrasil.com.br/noticias/100123116/ministro-marco-aurelio-vota-pelaabsolvicao-dos-seis-reus-acusados-de-lavagem-de-dinheiro>. 
LOPES, Alexsandro Broedel. Et al. Curso de Mercado Financeiro Tópicos Especiais. 1. Ed. São Paulo: Atlas, 2009.

MENDRONI, Marcelo. Crime de Lavagem de Dinheiro. São Paulo: Atlas, 2006.

MORO, Sergio Fernando. Crime de lavagem de dinheiro. São Paulo. Ed.Saraiva, 2010 .

PINOTTI, Maria Cristina. Corrupção: Lava Jato E Mãos Limpas. $1^{\circ}$ Ed. Portofolio Penguin. São Paulo, 2019.

TEBET, Diogo. Lei de lavagem de dinheiro e a extinção do rol dos crimes antecedentes. Boletim IBCRIM, Ano 20, nº 237, 2012. 